\title{
Optimization problems, first order approximated optimization problems and their connections
}

\section{EMILIA-LOREDANA POP and DOREL I. DUCA}

\section{ABSTRACT.}

In this paper, we attach to the optimization problem

$$
\begin{cases}\min & f(x) \\ \text { s. t. } & x \in X \\ & g(x) \leqq 0 \\ & h(x)=0,\end{cases}
$$

where $X$ is a subset of $\mathbb{R}^{n}, f: X \rightarrow \mathbb{R}, g=\left(g_{1}, \ldots, g_{m}\right): X \rightarrow \mathbb{R}^{m}$ and $h=\left(h_{1}, \ldots, h_{q}\right): X \rightarrow \mathbb{R}^{q}$ are functions, the $(0,1)-\eta-$ approximated optimization problem $(A P)$. We will study the connections between the optimal solutions for Problem $(A P)$, the saddle points for Problem $(A P)$, optimal solutions for Problem $(P)$ and saddle points for Problem $(P)$.

\author{
FACUlTy OF MATHEMATICS AND COMPUTER SCIENCE \\ "BABEŞ-BOLYAI UNIVERSITY" \\ M. KOGĂLNICEANU 1 \\ 400084 CLUJ-NAPOCA, ROMANIA \\ E-mail address: lory_pel@yahoo.com, emilia.pop@ubbcluj.ro \\ E-mail address: dorelduca@yahoo.com, dduca@math.ubbcluj.ro
}

